\title{
Adaptaçáo de um Programa de Ensino de Consciência Fonológica para Crianças com Paralisia Cerebral ${ }^{1}$ Adaptation of a Phonological Awareness Teaching Program for Children WITH CEREBRAL PALSY
}

\author{
Layse Maria dos Santos FERREIRA ${ }^{2}$ \\ Carmen Silvia Motta BANDINI ${ }^{3}$ \\ Heloisa Helena Motta BANDINI ${ }^{4}$
}

\begin{abstract}
RESUMO: Neste trabalho, propôs-se a adaptar um instrumento para ensinar consciência fonológica (CF) a crianças com Paralisia Cerebral (PC). PC consiste em um grupo de desordens do movimento e da postura, que pode estar associado a déficits cognitivos, de interação e de linguagem, comprometendo a independência funcional do indivíduo, tanto na modalidade oral quanto na escrita. A literatura afirma que, vocabulário, memória fonológica e CF são consideradas habilidades preditoras e necessárias à aquisição e ao desempenho em leitura e escrita. Participaram do estudo três crianças com diagnóstico de PC e dois juízes especialistas. O estudo foi dividido em quatro etapas: a) análise e adaptação do instrumento Alfabetização: Método Fônico; b) análise de juízes especialistas; c) estudo piloto com pré e pós teste de CF e leitura; e d) versão final do instrumento. Foram adaptadas 63 atividades, levando em consideração o perfil da população, a análise dos juízes e a aplicação a um grupo clínico. Os participantes conseguiram compreender e executar o treino em 26 das 33 atividades. Todos mostraram melhora nos escores quando comparados pré e pós testes. Diante disso, o instrumento mostrou-se adequado à populaçáo após a adaptaçáo e mostrou-se fiel ao ensino proposto pelo instrumento original.
\end{abstract}

PALAVRAS-CHAVE: Paralisia cerebral. Consciência fonológica. Educação Especial. Leitura.

\begin{abstract}
In this work, it was proposed to adapt an instrument to teach phonological awareness (PA) to children with Cerebral Palsy (CP). CP consists of a group of movement and posture disorders, which may be associated with cognitive, interaction and language deficits, compromising the individual's functional independence, both in oral and written form. Literature states that vocabulary, phonological memory and PA are considered predictive and necessary skills for acquisition and performance in reading and writing. Three children diagnosed with CP and two expert judges participated in the study. The study was divided into four stages: a) analysis and adaptation of the Literacy: Phonic Method; b) analysis carried out by expert judges; c) pilot study with pre and post CP test and reading; and d) final version of the instrument. Sixty-three activities were adapted, taking into account the population profile, the analysis carried out by the judges and the application to a clinical group. Participants were able to understand and execute the training in 26 of the 33 activities. All showed improvement in scores, when pre and post tests were compared. Therefore, the instrument proved to be suitable for the population after adaptation and was faithful to the teaching proposed by the original instrument.
\end{abstract}

KEYWORDS: Cerebral palsy. Phonological awareness. Special Education. Reading.

\footnotetext{
${ }^{1}$ https://doi.org/10.1590/1980-54702021v27e0115

${ }^{2}$ Psicóloga. Discente do Programa de Mestrado Profissional em Ensino na Saúde e Tecnologia da Universidade Estadual de Ciências da Saúde de Alagoas (UNCISAL). Alagoas/Brasil. E-mail: layse.msf2@gmail.com. ORCID: https://orcid.org/0000-00028315-2047

${ }^{3}$ Psicóloga. Doutora pela Universidade Federal de São Carlos (UFSCar). Docente do Programa de Mestrado em Ensino na Saúde e Tecnologia da Universidade Estadual de Ciências da Saúde de Alagoas (UNCISAL). Alagoas/Brasil. E-mail: csmbandini@gmail. com. ORCID: https://orcid.org/0000-0002-4731-5785

${ }^{4}$ Fonoaudióloga. Pós-doutora pela Universidade Federal de São Carlos. Docente do Programa de Mestrado em Ensino na Saúde e Tecnologia da Universidade Estadual de Ciências da Saúde de Alagoas (UNCISAL). Alagoas/Brasil. E-mail: heloisabandini@ gmail.com. ORCID: https://orcid.org/0000-0002-7320-2637
} 


\section{INTRODUÇÁo}

A paralisia cerebral (PC) consiste em um grupo de desordens do movimento e da postura, não progressivo, de caráter permanente e mutável, advinda de uma lesão cerebral primária que acomete o sistema nervoso central (SNC) imaturo ou em desenvolvimento no período pré, peri ou pós-natal (Rotta, 2002). Trata-se de uma encefalopatia crônica infantil, mais conhecida como PC, e tem como principal alteraçáo o déficit motor. A literatura aponta (Assis-Madeira \& Carvalho, 2009; Tabaquim et al., 2016) a associação da gravidade e do prejuízo motor a déficits funcionais em diferentes áreas, como em habilidades cognitivas, sensoriais, de comunicaçáo, comportamentais, de habilidades sociais, entre outras.

Dessa forma, a população com PC consiste em um grupo heterogêneo que apresenta alteraçóes clínicas diversas, variando de leves a graves. A classificação do quadro distingue-se de acordo com tipo de tônus, distribuição do acometimento no corpo e nível de independência, existindo diversas classificaçóes (Chagas et al., 2008). Em relação à classificação topográfica, em outras palavras, a distribuiçấo do acometimento no corpo, ela pode ser: hemiplégica, diplégica ou quadriplégica.

A inserção da pessoa com diagnóstico de PC na sociedade tem como alicerce a busca pela independência funcional. Para tanto, é fundamental propiciar a essa população. mecanismos de apropriação de conhecimento, de relaçóes sociais, de linguagem e experiências vividas, dentre elas a acadêmica. Para essa população, as barreiras impostas pelas alteraçôes clínicas tornam-se barreiras que impossibilitam o acesso a diversos contextos ricos em estímulos, e isso pode interferir no processo de apropriação de conhecimento. No entanto, a criança pode responder com dinamismo e eficácia a intervençóes favorecedoras de conhecimento quando diante de um contexto facilitador e estruturado (Tabaquim et al., 2016). Diante do exposto, é importante atentar para o desenvolvimento de habilidades de linguagem, tanto na forma oral quanto na forma escrita, pois essas habilidades possuem um papel de destaque na independência funcional do indivíduo.

Algumas habilidades de linguagem oral são consideradas preditoras para o desempenho posterior de leitura e de escrita, como consciência fonológica (CF), vocabulário, memória fonológica, consciência sintática e aritmética (Bandini et al., 2017; Capovilla et al., 2004; Capovilla \& Dias, 2008; Fragoso, 2019). CF consiste na capacidade de identificar, segmentar e manipular os sons da fala, nos níveis lexical (palavras) e sublexical (rimas, aliterações, sílabas e fonemas); consiste, assim, na habilidade de analisar a fala em seus segmentos sonoros, tornando-se habilidade básica a ser desenvolvida na alfabetização (Fragoso, 2019; Justino \& Barrera, 2012). Nesse contexto, estudos (Seabra \& Capovilla, 2010b; Capovilla et al., 2004) apontam que o déficit fonológico é a principal causa dos problemas na aquisição de leitura e de escrita e ressaltam a importância de intervir nesse aspecto, tanto em nível preventivo como remediativo.

As habilidades de leitura e de escrita são tarefas complexas que precisam de treino formal. Os estudos apontam (Andrade et al., 2014; Godoy et al., 2017; Seabra \& Dias, 2011) a eficiência do Método Fônico no ensino dessas habilidades, uma vez que o método privilegia o ensino explícito e sistemático das letras e dos fonemas, favorecendo habilidades essenciais ao desenvolvimento da $\mathrm{CF}$ e da associaçáo grafema-fonema, necessárias para a apropriaçáo do código alfabético e, consequentemente, para a aprendizagem da leitura e escrita . 
O Método Fônico vem sendo empregado em diversos estudos (Barby \& Guimarães, 2016; Brito, 2014; Fragoso, 2019; Freire, 2018; Pelosi et al., 2018) que apresentam resultados positivos na aprendizagem de leitura e de escrita em diversas populaçóes em diferentes séries, por meio da utilização de intervençóes baseadas no desenvolvimento de CF e correspondência grafema-fonema. No entanto, chama atenção o número pequeno de estudos que buscam ensinar essa habilidade à população com PC (Capovilla et al., 1998; Paixão, 2012).

Com base na necessidade de que as habilidades ligadas à CF sejam ensinadas para indivíduos com PC, a fim de promover e facilitar a aprendizagem de leitura e de escrita nessa população e diante do fato de que poucos são os métodos de ensino dessas habilidades, diretamente voltados para tais populaçóes, este estudo teve o objetivo de adaptar um método de ensino de CF proposto por Seabra e Capovilla (2010b), amplamente testado e com resultados satisfatórios com diversas populaçóes em ambiente escolar e clínico, para crianças com PC, utilizando, para isso, material de baixo custo e de fácil acesso a profissionais e responsáveis que convivem com crianças dessa população.

\section{Método}

Esta seção trata do perfil dos participantes do estudo, do local, dos procedimentos éticos e dos instrumentos utilizados para a coleta de dados. Por fim, as quatro etapas que fizeram parte do procedimento são descritas.

\subsection{Participantes}

O estudo contou com cinco participantes, inseridos nas Fases 2 e 3. A segunda fase teve a participação de dois especialistas. $\mathrm{O}(\mathrm{A})$ primeiro(a) era fonoaudiólogo(a), com experiência prática de 22 anos, professor(a), pós-doutor(a) em Educação Especial com atuação em Educação Especial nos seguintes temas: deficiência auditiva, leitura e escrita. Já o(a) segundo(a) era fonoaudiólogo(a), com experiência prática de 17 anos, supervisor(a) de estágio e mestre(a) em distúrbios da comunicação humana com atuação nas áreas de fonoaudiologia nos seguintes temas: linguagem e audiologia.

A Fase 3 contou com a participação de três crianças: P1, do sexo masculino, com 9 anos e 11 meses; P2, do sexo feminino, com 6 anos e 8 meses; e P3, do sexo masculino, com 8 anos e 4 meses de idade no início do estudo. Todos eram oralizados; desse modo, apresentavam comportamentos vocais inteligíveis por terceiros, porém com trocas fonêmicas. Tinham diagnóstico de PC, estavam inseridos na Educação Infantil em escola pública regular (P1 no $4^{\circ}$ ano, P2 no $2^{\circ}$ e P3 no $3^{\circ}$ ) e eram atendidos na instituição na qual o estudo foi realizado desde 2017, 2014 e 2015, respectivamente. Os três participantes foram avaliados inicialmente com classificação muito baixa pela Prova de Consciência Fonológica por Figuras (PCFF) de Seabra e Capovilla (2012).

\subsection{LOCAL}

A pesquisa foi realizada em uma instituição credenciada como um Centro Especializado em Reabilitação pelo Ministério da Saúde na cidade de Maceió - (CER III). A coleta de dados foi realizada na sala de Psicologia do serviço, ambiente familiar às crianças 
participantes. A sala possuía isolamento acústico, era iluminada artificialmente e climatizada com um ar-condicionado.

\subsection{Procedimentos éticos}

O projeto faz parte de um estudo maior aprovado pelo Comitê de Ética e Pesquisa da Universidade Estadual de Ciências da Saúde de Alagoas. O Termo de Consentimento Livre e Esclarecido (TCLE) foi entregue aos especialistas e aos responsáveis pelas crianças, lido, explicado e esclarecidas as dúvidas, quando solicitado. Os responsáveis autorizaram a participação dos menores no estudo. O Termo de Assentimento Livre Esclarecido (TALE) foi lido e explicado a cada criança participante, assim como dirimidas as dúvidas por elas apresentadas. Posteriormente a tais explicaçóes, foram recolhidos os consentimentos, de forma lúdica, por meio de pintura a dedo.

\subsection{INSTRUMENTOS DE COLETA DE DADOS}

Nesta seção, os instrumentos de coleta de dados são descritos, a saber: Parecer dos especialistas; Prova de consciência fonológica por figuras (Seabra \& Capovilla, 2012); Teste de competência de leitura de palavras e pseudopalavras (Seabra \& Capovilla, 2010a); Livro Alfabetização: Método Fônico (Seabra \& Capovilla, 2010b); e, por fim, as atividades de ensino para o estudo piloto

\subsubsection{Parecer dos especialistas}

O protocolo preenchido pelos pareceristas foi desenvolvido pelas autoras de forma a permitir que eles pudessem avaliar a adequação das atividades adaptadas à população com PC. Foi composto pelas 63 atividades, apresentadas por Seabra e Capovilla (2010b), adaptadas, e foi apresentado aos pareceristas em um arquivo de programa Word. As adaptaçóes realizadas foram feitas a partir da leitura criteriosa das características da população com PC, dos aspectos que envolvem $\mathrm{CF}$ e da posterior análise das atividades do programa de ensino de CF presente no livro Alfabetização: Método Fônico (Seabra \& Capovilla, 2010b). Com base nisso, foram realizadas adaptaçóes para grande parte das atividades sugeridas pelo livro, quando este se propunha a ensinar: consciência de palavras, rima, aliteração, consciência silábica, identidade fonêmica e consciência fonêmica.

As adaptações foram classificadas em cinco categorias, baseando-se no estudo de Fontoura et al. (2011), cuja população possui características de comunicação oral similares ao da população estudada nesta pesquisa. As categorias consistem em: a) dupla forma de obtenção de resposta: composta por atividades em que a aplicação se manteve igual e foi modificada apenas a forma de obtenção da resposta, em que foi mantida a forma original de resposta para cada atividade e, concomitantemente, era solicitada outra opção de resposta adaptada, como critério de comparação; assim, a criança não tinha a opção de escolha, ela respondia às atividades dessa categoria utilizando as duas formas de obtenção de resposta; b) modificação na obtenção da resposta: composta por atividades em que a forma de aplicação se manteve idêntica ao original, sendo modificada apenas a forma de obtenção de resposta dos participantes; nesse caso, em relação às atividades que exigiam habilidades manuais, foram dadas duas opções de resposta 
ao participante, sendo possível escolher uma ou outra; c) modificação na forma de aplicação e de obtenção da resposta: composta por atividades em que foram realizadas adaptaçóes na aplicação, assim como na forma de obtenção da resposta; desse modo, a depender da atividade, a obtenção da resposta poderia ser totalmente modificada e, em outras, era utilizada a dupla forma de obtenção da resposta; d) modificação da forma de aplicação: composta por atividades em que foi modificada apenas a forma de aplicação, mantendo as formas de resposta propostas pelo treino original; por fim, e) mantida inalterada: composta por atividades que não foram alteradas, em relação ao treino original, já que não exigiam dos participantes comportamentos verbais ou motores complexos.

\subsubsection{Prova DE CONSCIÊNCIA FONOLÓGICA POR FIGURAS}

A Prova de consciência fonológica por figuras (Seabra \& Capovilla, 2012) foi realizada como critério para inclusão no estudo. Por meio dela, avalia-se a habilidade de discriminar e manipular os sons da fala, utilizando respostas não vocais - o teste permite, assim, avaliar CF em crianças que apresentam alteraçóes de fala. A Prova de consciência fonológica por figuras é composta por nove subtestes, que avaliam habilidades como: rima, aliteração, adição, subtração e transposição silábica, adição, subtração e transposição fonêmica e trocadilhos. Cada subteste possui dois itens de treino e cinco de teste, em que, diante da palavra falada pelo avaliador, a criança precisa escolher, dentre cinco figuras, a correspondente à palavra, a depender da habilidade avaliada. Os resultados são computados com base na quantidade de respostas corretas. Cada resposta correta equivale a um ponto; assim sendo, a criança pode acumular no máximo 45 pontos. A classificação final tem como parâmetro: 1) Pontuação padrão < 70 = muito baixa; 2) pontuação padrão entre 70 e 84 = baixa; 3) pontuação padrão entre 85 e 114 = média; 4) pontuação padrão 115 a 129 = alta; 5) pontuação padrão $\geq$ a 130 = muito alta.

\subsubsection{TeSTE DE COMPETÊNCIA DE LEITURA DE PALAVRAS E PSEUdOPALAVRAS}

Com o Teste de competência de leitura de palavras e pseudopalavras (Seabra \& Capovilla, 2010a), avalia-se o estágio de desenvolvimento da leitura, tendo como parâmetro as etapas: logográfica, alfabética e ortográfica. Utiliza-se como material papel e lápis e é composto por 78 itens (oito de treino e 70 de teste), em que cada item é composto por uma figura e um item escrito (palavra ou pseudopalavra). A criança precisa ler o item escrito e circular quando estiver correto em termos ortográficos e semânticos e marcar um "x" nos incorretos, de acordo com o mesmo critério. A classificação final tem como referência os seguintes critérios: a) pontuação-padrão abaixo de 70: muito baixa; b) pontuação-padrão entre 70 e 84: baixa; c) pontuação-padrão entre 85 e 114: média; d) pontuação-padrão entre 115 e 129; e) pontuação-padrão igual ou superior a 130: muito alta.

\subsubsection{Livro AlfabetizaÇÃo: MÉtodo Fônico}

O livro Alfabetização: Método Fônico (Seabra \& Capovilla, 2010b) contém um programa composto de atividades que buscam desenvolver três grandes competências: CF (43 atividades principais, das quais 20 se subdividem em duas tarefas, totalizando 63 atividades), conhecimento das correspondências grafonêmicas (59 atividades) e produção e interpretação 
de textos (25 atividades) (ver Tabela 1). As atividades inseridas no livro apresentavam um grau de complexidade crescente e eram apresentadas de forma alternada por competências no decorrer do programa, possibilitando ao aluno desafios maiores, em todas as competências treinadas, com base no que ia sendo alcançando durante o treino e no seu nível de conhecimento. Essas atividades já foram amplamente aplicadas e testadas por educadores, pesquisadores e profissionais com crianças de diversas populaçóes, cuja eficácia foi verificada (Andrade et al., 2014; Brito, 2014).

\section{Tabela 1}

\section{Apresentação das atividades de ensino do programa "Alfabetização: Método Fônico"}

\begin{tabular}{|c|c|c|}
\hline & Atividades de consciência fonológica & \\
\hline Habilidade & Objetivo & No \\
\hline \multirow{4}{*}{ Consciência de palavras } & Segmentação de frases & 3 \\
\hline & Espaçamento entre palavras de frases e contagem do número de palavras & 1 \\
\hline & Substituição de palavras & 1 \\
\hline & Substituição de pseudopalavras por palavras & 1 \\
\hline \multirow{5}{*}{ Rima } & Produção oral de palavras que rimam & 1 \\
\hline & Identificação de figuras cujos nomes rimam & 1 \\
\hline & Complementação de palavras escritas que rimam & 1 \\
\hline & Classificação de figuras conforme a terminação de seus nomes falados & 2 \\
\hline & $\begin{array}{l}\text { Manipulaçáo de formas geométricas representando os sons das palavras e pseudopa- } \\
\text { lavras }\end{array}$ & 2 \\
\hline \multirow{4}{*}{ Aliteração } & Produção oral de palavras que aliteram & 1 \\
\hline & Complementação de palavras escritas que aliteram & 1 \\
\hline & Classificação de figuras conforme a terminação de seus nomes falados & 1 \\
\hline & $\begin{array}{l}\text { Manipulação de formas geométricas representando os sons de palavras e pseudopa- } \\
\text { lavras }\end{array}$ & 2 \\
\hline Rima e aliteração & Escolha de figuras cujos nomes rimam ou aliteram com um modelo & 1 \\
\hline \multirow{6}{*}{ Consciência silábica } & Marcaçáo de sílabas em cançôes & 1 \\
\hline & Contagem de sílabas & 3 \\
\hline & Jogo do percurso & 1 \\
\hline & Adição e subtração de sílabas & 1 \\
\hline & Síntese de sílabas & 1 \\
\hline & Transposição de sílabas & 1 \\
\hline \multirow{3}{*}{ Identidade fonêmica } & Identificação de fonema & 1 \\
\hline & Dominó de figuras & 1 \\
\hline & Escolha de figuras cujos nomes comecem com o mesmo som de um desenho modelo & 1 \\
\hline
\end{tabular}




\begin{tabular}{llc}
\hline & Atividades de consciência fonológica & No \\
\hline Habilidade & Objetivo & 1 \\
\hline & Correção de palavras com trocas fonêmicas & 2 \\
& Síntese de fonemas & 1 \\
& Substituição de vogais em palavras & 2 \\
& Análise de fonemas & 1 \\
Consciência fonêmica & Adição de fonemas & 1 \\
& Substituição de fonemas & 1 \\
& Adição e subtração de fonemas & 1 \\
& Contagem e manipulação de fonemas & 2 \\
& Inversão de fonemas & 1 \\
Alfabeto inventado & 1 \\
\hline
\end{tabular}

Nota. A tabela apresenta as atividades de consciência fonológica, subdivididas por competências, sugeridas no livro Alfabetização: Método Fônico (Seabra \& Capovilla, 2010b).

\subsubsection{ATIVIDADES DE ENSINO PARA O ESTUDO PILOTO}

Foi utilizada uma versão reduzida, contendo apenas 33 atividades das 63 propostas no parecer analisado pelos especialistas, para o ensino de CF para as crianças com PC. O programa de ensino de CF, adaptado para crianças com PC, foi composto por: a) protocolos de aplicação para seis competências (consciência de palavras, rima, aliteração, consciência silábica, identificação fonêmica, consciência fonêmica); e b) material de aplicação de cada atividade. Os protocolos contavam com a categoria a qual a atividade se enquadrava, a forma de aplicaçáo e a coleta de respostas pelo aplicador, a instruçáo inicial, a cada tentativa e final; além disso, um campo ao aplicador para avaliação da atividade.

\subsection{Procedimento}

O estudo foi realizado em quatro etapas conforme mostra a Figura 1.

\section{Figura 1}

Estrutura e sequência do procedimento descrito no estudo

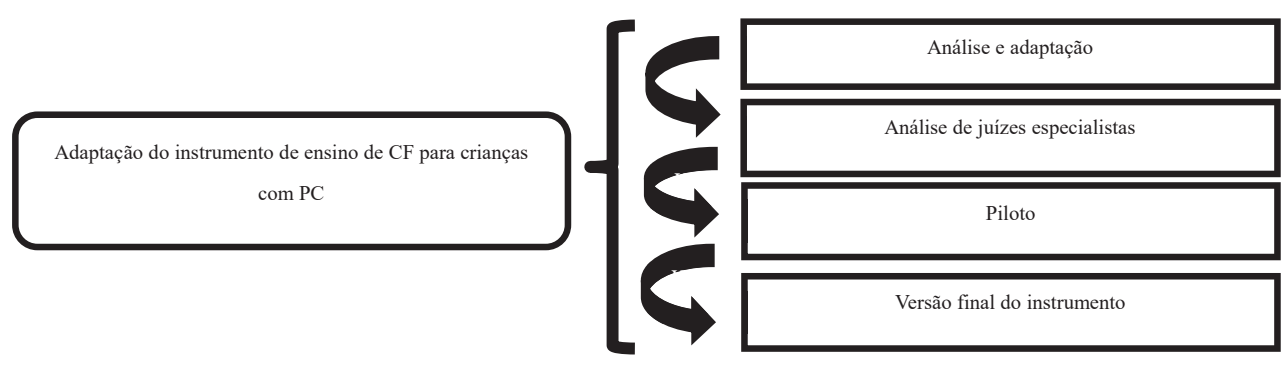




\subsubsection{ETAPa 1- ANÁlise E ADAPTAÇÃo do PROGRAMA DE TREINO}

Realizou-se a leitura das atividades e consequente análise do programa de treino proposto no livro Alfabetização: Método Fônico (Seabra \& Capovilla, 2010b). A análise teve o objetivo de avaliar a necessidade de modificaçóes nas atividades propostas pelo instrumento, quando aplicado a crianças com PC, visando manter o objetivo da tarefa, a saber: desenvolver competência de CF em crianças com PC. Nessa fase, foi construída a primeira versão do programa adaptado às crianças com PC, a qual foi encaminhada aos juízes especialistas para análise.

\subsubsection{Etapa 2- ANÁlise POR JUízes especialistas EM CF}

Nessa etapa, foi solicitado que juízes especialistas respondessem a um parecer, em que eram apresentados: o objetivo da atividade segundo o instrumento original; a descrição da atividade original e a adaptação sugerida pela pesquisadora. Assim sendo, eram apresentadas as atividades originais e as adaptadas para comparação. Foi solicitado, em um campo ao final da apresentação de cada atividade, que os juízes respondessem a alguns questionamentos em que comparavam e avaliavam cada atividade adaptada com a original: 1) A adaptação se mostra adequada?; 2) A tarefa adaptada continua ensinando a habilidade?; 3) Você sugere alguma adaptação? Caso a resposta a algum dos dois primeiros questionamentos fosse "não", a última pergunta possibilitaria sugestóes.

\subsubsection{ETAPa 3- Estudo piloto}

Essa etapa procurou testar o procedimento de ensino em situação real, após as modificaçóes sugeridas pelos especialistas terem sido realizadas, verificando possíveis falhas e adequações das atividades. Ocorreu em 30 sessóes em média, com duração de 30 minutos, duas vezes por semana, em horários alternados aos das terapias realizadas pelas crianças na instituição, durante cinco meses, seguindo a sequência de protocolo das atividades a depender do desempenho da criança. Desse modo, se ela concluísse uma atividade, era realizada consequência final pré-determinada para a atividade, conforme o protocolo; e, então, seguindo para a próxima tarefa.

Para cada bloco de atividades subdividido por competências (consciência de palavras, rima, aliteração, consciência silábica, identidade fonêmica e consciência fonêmica), foi retirado um percentual, totalizando 33 atividades, do parecer avaliado pelos juízes especialistas e aplicado à amostra piloto selecionada para este estudo. A seleção das atividades teve como critério a semelhança no objetivo, na aplicação e nas respostas esperadas dos participantes. Dessa forma, as atividades que possuíam tarefas iguais ou muito semelhantes foram propostas à criança apenas uma vez. Buscou-se verificar se todos os termos estavam compreensíveis, se a instrução estava adequada e se a criança conseguia executar a tarefa proposta à cada aplicação. Para isso, ao final de cada atividade, o pesquisador respondia a um campo no protocolo de atividade piloto, que questionava se a criança conseguiu: 1) compreender a instrução; 2) compreender a tarefa; e 3) quais as modificações necessárias. Além disso, foi analisada a pontuação bruta dos acertos a cada tentativa em todas as tarefas. 


\subsubsection{ETAPA 4- VERSÁO FINAL dO PROCEDIMENTO DE ENSINO ADAPTADO}

A versão final do instrumento foi construída após as modificações sugeridas pelos juízes, a aplicação à população clínica com PC e as modificações realizadas das necessidades apresentadas depois da aplicação à população clínica.

\section{Resultados}

$\mathrm{Na}$ Fase 1, foram adaptadas 63 atividades, subdivididas por categorias, oriundas do estudo de Fontoura et al. (2011), apresentadas na Tabela 2.

\section{Tabela 2}

Total bruto e percentagem do número de atividades, por habilidade, apresentadas por categorias

\begin{tabular}{|c|c|c|c|c|c|c|c|}
\hline \multicolumn{8}{|c|}{ Habilidades } \\
\hline & Rima & Alit. & $\mathrm{CP}$ & CS & IF & CF & Total \\
\hline \multicolumn{8}{|c|}{ Dupla forma de obtençấo de resposta } \\
\hline Atividades & $1,2,3,8$ & $1,2,3,8$ & $1,6,7,8$ & $3,6,8$ & 1 e 2 & $\begin{array}{l}1,2,3,4,5,12,14,15 \\
18,19,20,21,22\end{array}$ & 30 \\
\hline$\%$ & $40 \%$ & $45 \%$ & $50 \%$ & $38 \%$ & $33 \%$ & $59 \%$ & \\
\hline
\end{tabular}

Modificaçáo na obtençáo da resposta

$\begin{array}{llllllll}\text { Atividades } & 4,5,7,10 & 4,6,7,9 & 2 \text { e } 3 & 1 & 3 \text { e } 6 & 6,7,8,9,10,11,16,17 & 21 \\ \% & 40 \% & 45 \% & 25 \% & 12 \% & 33 \% & 36 \%\end{array}$

Modificaçáo da forma de aplicação e de obtençáo de resposta

\begin{tabular}{llllllll}
\hline Atividades & 6 e 9 & 5 & 5 & 2 e 7 & - & 13 & 7 \\
$\%$ & $20 \%$ & $11 \%$ & $12 \%$ & $25 \%$ & $0 \%$ & $5 \%$ &
\end{tabular}

Modificação da forma de aplicaçáo

\begin{tabular}{llllllll}
\hline Atividades & - & - & 4 & - & 4 & - \\
\\
$\%$ & $0 \%$ & $0 \%$ & $12 \%$ & $0 \%$ & $17 \%$ & $0 \%$ \\
\hline Atividades & - & & Mantidas inalteradas & 3 \\
$\%$ & $0 \%$ & $0 \%$ & $0 \%$ & 4 e 5 & 5 & - & $0 \%$ \\
\hline Total & 10 & 9 & 8 & $25 \%$ & $17 \%$ & $0 \%$ \\
\hline
\end{tabular}

Nota. A tabela apresenta o total de atividades inseridas nas categorias de Rima, Aliteraçáo (Alit), consciência de palavras (CP), consciência de silabas (CS), identidade fonêmica (IF) e consciência fonêmica (CF), bem como o total de atividades por habilidades ensinadas e a percentagem do número de atividades, por habilidade, apresentadas dentro de cada categoria.

Trinta atividades foram adaptadas em relação à obtenção da resposta para que fossem realizadas de duas formas concomitantemente; em 21 , as modificaçóes foram realizadas quanto à obtenção da resposta; sete delas modificaram a forma de aplicação e obtenção da resposta; 
duas foram modificadas unicamente a forma de aplicação; e três atividades mantiveram-se iguais às originais, tanto em relação à aplicação quanto à forma de resposta. $\mathrm{Na}$ Tabela 2, o total de atividades inseridas nas categorias foi apresentado subdividido por habilidades treinadas, assim como foi calculado o percentual de atividades por habilidade, inseridas por categorias. As atividades de rima concentraram-se nas categorias dupla forma de obtenção de resposta (40\%) e modificação na obtenção da resposta (40\%). O mesmo se deu em aliteração (45\%). Em consciência de palavras e consciência fonêmica, as atividades concentraram-se na dupla forma de obtenção de resposta, tendo percentuais de 50\% e 59\%, respectivamente; e consciência silábica e identidade fonêmica tiveram suas atividades subdivididas entre grande parte das categorias.

$\mathrm{Na}$ Fase 2, os juízes especialistas avaliaram as adaptações, seguindo dois critérios: a adequação da atividade à população e ao conteúdo - desse modo, eles avaliaram se a adaptação se mostrava adequada à população com $\mathrm{PC}$ e se a atividade adaptada continuava ensinando a habilidade que se propunha a ensinar. Verificou-se uma concordância entre os juízes de 89\%, calculadas por meio da fórmula: $\mathrm{IC}=$ Concordância /concordância + discordância x 100. Foi considerada como concordância quando os juízes respondiam de forma idêntica aos dois itens presentes no parecer. As discordâncias existiram em sete atividades em um total de 63. Em duas atividades, um dos juízes apresentou sugestóes de alteraçóes mesmo que considerando a atividade adequada; dessa maneira, foram feitas nove sugestóes no total (ver Tabela 3), das quais duas não representaram discordância entre os especialistas, sendo apresentadas como sugestão.

\section{Tabela 3}

\section{Tabela de descrição das sugestóes apresentadas pelos juizes}

\begin{tabular}{|c|c|c|c|c|c|}
\hline & AT & Análise do juiz & $\begin{array}{l}\text { Categoria } \\
\text { inserida }\end{array}$ & $\begin{array}{l}\text { Atividade adaptada } \\
\text { antes da análise }\end{array}$ & Adequação pós-análise \\
\hline Rima & $\begin{array}{l}1 \\
2 \\
3\end{array}$ & $\begin{array}{l}\text { Mudança nos termos } \\
\text { dos objetivos das } \\
\text { atividades. }\end{array}$ & $\begin{array}{l}\text { Dupla forma } \\
\text { de obtenção de } \\
\text { resposta. }\end{array}$ & $\begin{array}{l}\text { Grafia do objetivo: } \\
\text { Produçáo oral das } \\
\text { palavras que rimam. }\end{array}$ & $\begin{array}{l}\text { Grafia do objetivo: Produção } \\
\text { de rima. }\end{array}$ \\
\hline Aliteração & $\begin{array}{l}1 \\
2 \\
3\end{array}$ & $\begin{array}{l}\text { Mudança nos termos } \\
\text { dos objetivos das } \\
\text { atividades. }\end{array}$ & $\begin{array}{l}\text { Dupla forma } \\
\text { de obtenção de } \\
\text { resposta. }\end{array}$ & $\begin{array}{l}\text { Grafia do objetivo: } \\
\text { Produçáo oral das } \\
\text { palavras que aliteram. }\end{array}$ & $\begin{array}{l}\text { Grafia do objetivo: Produçáo } \\
\text { de aliteraçáo. }\end{array}$ \\
\hline $\begin{array}{l}\text { Consciên- } \\
\text { cia silábica }\end{array}$ & 3 & $\begin{array}{l}\text { Não corresponde à } \\
\text { proposta da nomea- } \\
\text { ção oral. }\end{array}$ & $\begin{array}{l}\text { Dupla forma } \\
\text { de obtenção de } \\
\text { resposta. }\end{array}$ & $\begin{array}{l}\text { Grafia do objetivo: } \\
\text { Contagem de sílabas } \\
\text { durante a nomeação } \\
\text { oral de figuras. }\end{array}$ & $\begin{array}{l}\text { Grafia do objetivo: Contagem } \\
\text { de sílabas de nome de figuras. }\end{array}$ \\
\hline $\begin{array}{l}\text { Cons- } \\
\text { ciência } \\
\text { Fonêmica }\end{array}$ & 1 & $\begin{array}{l}\text { Mudança nos termos } \\
\text { dos objetivos das } \\
\text { atividades. }\end{array}$ & $\begin{array}{l}\text { Dupla forma } \\
\text { de obtenção de } \\
\text { resposta. }\end{array}$ & $\begin{array}{l}\text { Correção de palavras } \\
\text { com trocas fonêmicas. }\end{array}$ & $\begin{array}{l}\text { Identificação de palavras com } \\
\text { trocas fonêmicas. }\end{array}$ \\
\hline $\begin{array}{l}\text { Cons- } \\
\text { ciência } \\
\text { Fonêmica }\end{array}$ & 3 & $\begin{array}{l}\text { A criança nấo está } \\
\text { executando a ativi- } \\
\text { dade. }\end{array}$ & $\begin{array}{l}\text { Dupla forma } \\
\text { de obtenção de } \\
\text { resposta. }\end{array}$ & $\begin{array}{l}\text { 1. Pesquisadora: Mú- } \\
\text { sica original/ trocando } \\
\text { as vogais/ com pausas/ } \\
\text { discussão ao final. } \\
\text { 2. A criança e o adul- } \\
\text { to: cantam a música } \\
\text { trocando as vogais das } \\
\text { palavras. }\end{array}$ & $\begin{array}{l}\text { 1. Pesquisadora: música origi- } \\
\text { nal/ trocando as vogais. } \\
\text { 2. A criança: } \\
\text { Barulho na identificação da } \\
\text { troca / escolhe entre sons qual } \\
\text { o som trocado. }\end{array}$ \\
\hline
\end{tabular}

Nota. A tabela apresenta as habilidades, a ordem de apresentação das atividades (AT), a categoria inserida e as atividades adaptadas e modificadas pós-análise dos juízes. 
Cabe ressaltar que as atividades apresentadas com sugestóes de modificação pelos juízes enquadram-se na categoria de dupla obtenção de resposta; assim sendo, a criança deveria responder de forma vocal e não vocal, já que as crianças participantes deste estudo eram oralizadas, apesar de pouco fluentes, o que possibilitou a participação e a resposta vocal em atividades que exigiam delas correção de palavras ou fonêmicas.

O estudo piloto, Fase 3, contou com 33 atividades e ocorreu em 30 sessões em média (P1 com 33 sessóes e P2 e P3 com 29 sessóes); assim, cada criança realizou aproximadamente uma atividade por sessão. Dessas, apenas em três atividades as crianças não conseguiram executar as tarefas, duas inseridas em consciência de palavras (Atividades 3 e 5) e uma em consciência silábica (Atividade 5), ambas exigiam competências aritméticas (senso numérico) e uma criança (P1) apresentou dificuldade de executá-la (ver Tabela 4). Foram consideradas não executadas as atividades em que a criança conseguia compreender o comando, esforçava-se para executar, mas não conseguia realizar nenhum item, em decorrência de dificuldade em habilidades diversas como habilidades motoras ou em aritmética.

\section{Tabela 4}

Tabela de porcentagem de acertos por tentativas nas habilidades ensinadas

\begin{tabular}{|c|c|c|c|c|c|c|c|c|c|c|c|c|}
\hline \multirow[b]{2}{*}{ Rima } & \multicolumn{3}{|c|}{ P1_ } & \multirow[b]{2}{*}{$\mathrm{N}$} & \multicolumn{3}{|c|}{ P2 } & \multirow[b]{2}{*}{$\mathrm{N}$} & \multicolumn{3}{|c|}{ P3 } & \multirow[b]{2}{*}{$\mathrm{N}$} \\
\hline & $1^{\circ}$ & $2^{\circ}$ & $3^{\circ}$ & & $1^{\circ}$ & $2^{\circ}$ & $3^{\circ}$ & & $1^{\circ}$ & $2^{\circ}$ & $3^{\circ}$ & \\
\hline AT 1 & 36 & 28 & 36 & 0 & 100 & - & - & 0 & 82 & 18 & - & 0 \\
\hline AT 4 & 0 & 0 & 100 & 0 & 0 & 0 & 100 & 0 & 100 & - & - & 0 \\
\hline AT 6 & 25 & 21 & 54 & 0 & 100 & - & - & 0 & 75 & 25 & - & 0 \\
\hline AT 7 & 100 & - & - & 0 & 100 & - & - & 0 & 100 & - & - & 0 \\
\hline AT 8 & 100 & - & - & 0 & 100 & - & - & 0 & 100 & - & - & 0 \\
\hline Aliteração & $1^{\circ}$ & $2^{\circ}$ & $3^{\circ}$ & $\mathrm{N}$ & $1^{\circ}$ & $2^{\circ}$ & $3^{\circ}$ & $\mathrm{N}$ & $1^{\circ}$ & $2^{\circ}$ & $3^{\circ}$ & $\mathrm{N}$ \\
\hline AT 3 & 67 & 33 & - & 0 & 0 & 100 & - & 0 & 71 & 29 & - & 0 \\
\hline AT 4 & 19 & 28 & 55 & 0 & 82 & 18 & - & 0 & 86 & 14 & - & 0 \\
\hline AT 6 e 7 & 100 & - & - & 0 & 100 & - & - & 0 & 62 & 3 & 0 & 34 \\
\hline AT 8 & 100 & - & - & 0 & 100 & - & - & 0 & 100 & - & - & 0 \\
\hline Consciência de palavras & $1^{\circ}$ & $2^{\circ}$ & $3^{\circ}$ & $\mathrm{N}$ & $1^{\circ}$ & $2^{\circ}$ & $3^{\circ}$ & $\mathrm{N}$ & $1^{\circ}$ & $2^{\circ}$ & $3^{\circ}$ & $\mathrm{N}$ \\
\hline AT 1 & 100 & - & - & 0 & 100 & - & - & 0 & 83 & 17 & - & 0 \\
\hline AT 3 & 0 & 0 & 0 & 100 & 60 & 40 & - & 0 & 0 & 80 & 20 & 0 \\
\hline AT5 & 0 & 0 & 0 & 100 & 23 & 62 & 15 & 0 & 0 & 61 & 38 & 0 \\
\hline AT8 & 0 & 31 & 0 & 69 & 85 & 15 & - & 0 & 100 & - & - & 0 \\
\hline Consciência silábica & $1^{\circ}$ & $2^{\circ}$ & $3^{\circ}$ & $\mathrm{N}$ & $1^{\circ}$ & $2^{\circ}$ & $3^{\circ}$ & $\mathrm{N}$ & $1^{\circ}$ & $2^{\circ}$ & $3^{\circ}$ & $\mathrm{N}$ \\
\hline ATb1 & 0 & 100 & - & 0 & 0 & 100 & - & 0 & 0 & 100 & - & 0 \\
\hline AT 5 & 0 & 0 & 0 & 100 & 100 & - & - & 0 & 100 & - & - & 0 \\
\hline AT 6 e 7 & 37 & 37 & 25 & 0 & 81 & 18 & - & 0 & 50 & 25 & 25 & 0 \\
\hline AT 8 & 31 & 31 & 37 & 0 & 94 & 6 & - & 0 & 69 & 31 & - & 0 \\
\hline Identidade fonêmica & $1^{\mathrm{a}}$ & $2^{\mathrm{a}}$ & $3^{a}$ & $\mathrm{~N}$ & $1^{\mathrm{a}}$ & $2^{\mathrm{a}}$ & $3^{\mathrm{a}}$ & $\mathrm{N}$ & $1^{\mathrm{a}}$ & $2^{a}$ & $3^{a}$ & $\mathrm{~N}$ \\
\hline
\end{tabular}




\begin{tabular}{|c|c|c|c|c|c|c|c|c|c|c|c|c|}
\hline \multirow[b]{2}{*}{ AT 1} & \multicolumn{4}{|c|}{ P1_ } & \multicolumn{3}{|c|}{ P2 } & \multirow[b]{2}{*}{0} & \multicolumn{3}{|c|}{ P3 } & \multirow[b]{2}{*}{0} \\
\hline & 100 & - & - & 0 & 87 & 12 & - & & 100 & - & - & \\
\hline AT 2 & 0 & 100 & - & 0 & 100 & - & - & 0 & 0 & 100 & - & 0 \\
\hline AT 3 & 25 & 25 & 50 & 0 & 50 & 25 & 25 & 0 & 37 & 25 & 37 & 0 \\
\hline AT 5 & 19 & 31 & 47 & 0 & 87 & 12 & - & 0 & 50 & 25 & 6 & 31 \\
\hline AT 6 & 0 & 29 & 71 & 0 & 100 & - & - & 0 & 43 & 29 & 28 & 0 \\
\hline Consciência fonêmica & $1^{\circ}$ & $2^{\circ}$ & $3^{\circ}$ & $\mathrm{N}$ & $1^{\circ}$ & $2^{\circ}$ & $3^{\circ}$ & $\mathrm{N}$ & $1^{\circ}$ & $2^{\circ}$ & $3^{\circ}$ & $\mathrm{N}$ \\
\hline AT 1 & 19 & 44 & 37 & 0 & 16 & 100 & - & 0 & 0 & 75 & 25 & 0 \\
\hline AT 3 & 40 & 60 & - & 0 & 100 & - & - & 0 & 100 & - & - & 0 \\
\hline AT 5 & 29 & 35 & 35 & 0 & 94 & 6 & - & 0 & 100 & - & - & 0 \\
\hline AT 8 & 0 & 0 & 25 & 75 & 0 & 100 & - & 0 & 37 & 25 & 25 & 12 \\
\hline AT 9 & 5 & 26 & 30 & 0 & 100 & - & - & 0 & 64 & 35 & - & 0 \\
\hline AT 16 e 17 & 0 & 0 & 44 & 55 & 77 & 22 & - & 0 & 44 & 22 & 22 & 11 \\
\hline AT 20 & 12 & 87 & - & 0 & 100 & - & - & 0 & 100 & - & - & 0 \\
\hline AT 21 & 11 & 22 & 22 & 44 & 78 & 22 & - & 0 & 33 & 22 & 44 & 0 \\
\hline
\end{tabular}

Nota. A tabela apresenta as atividades (AT) subdivididas por habilidades, e o percentual de desempenho de cada participante (P1, P2, P3) nas três tentativas apresentadas durante o ensino, assim como o percentual dos que não conseguiram responder ao item proposto $(\mathrm{N})$.

A exemplo da Atividade 5 de consciência silábica, todas as atividades não executadas foram readaptadas. A Atividade 5 foi inserida na categoria "dupla forma de obtenção de resposta", pois possibilitava ao participante executar a atividade utilizando a segunda forma de resposta - isso diminuiu a tensão, possibilitando a execução da tarefa. Nas atividades em que se exigia da criança apontar o número final de sílabas presentes em palavras ou relacionar figuras com o número de sílabas, colocando-as em caixas de acordo com o número, permitiu-se que a criança dissesse separadamente cada sílaba e batesse palmas, e a experimentadora contava, possibilitando ao fim da atividade apontar junto ao participante o número ou inserir a figura na caixa correspondente.

Algumas atividades apresentaram um percentual de erros não corrigidos mesmo após três tentativas com instrução; dessa forma, as crianças conseguiram compreender e executar a atividade, porém precisariam de um período maior de treino para concluir. Como é possível observar na Tabela 4, isso se deu nas atividades de consciência de palavras (AT8), aliteração (AT 6 e 7), identidade fonêmica (AT3 e 5), consciência fonêmica (AT8, 16 e 17, 21).

Em relação aos acertos por tentativas, as atividades de rima e aliteração apresentaram um percentual maior de acertos na primeira tentativa; já as atividades de identificação fonêmica e consciência fonêmica necessitaram de mais tentativas para acertos dos itens, demonstrando mais dificuldades entre os participantes.

Outro fator importante a considerar foi o desempenho dos participantes nas avaliaçóes iniciais e finais. Mesmo sendo aplicada uma versão reduzida do programa de ensino, foi possível observar aprimoramento na habilidade treinada (ver Tabela 5). 


\section{Tabela 5}

Desempenho dos participantes na PCFF E TCLPP

\begin{tabular}{|c|c|c|c|c|c|c|}
\hline Participante & Idade & Ano & $\begin{array}{c}\text { Pré-teste } \\
\text { PCFF }\end{array}$ & $\begin{array}{c}\text { Pós-teste } \\
\text { PCFF }\end{array}$ & $\begin{array}{c}\text { Pré-teste } \\
\text { TCLPP }\end{array}$ & $\begin{array}{c}\text { Pós-teste } \\
\text { TCLPP }\end{array}$ \\
\hline P1 & $9 \mathrm{a}$ e $11 \mathrm{~m}$ & $4^{\circ}$ & Muito baixa (7) & Muito baixa (15) & Muito baixa (31) & Muito baixa (36) \\
\hline P2 & $6 a$ e $8 m$ & $2^{\circ}$ & Muito baixa (32) & Média (39) & Média (56) & Média (57) \\
\hline $\mathrm{P} 3$ & $8 \mathrm{a}$ e $4 \mathrm{~m}$ & $3^{\circ}$ & Muito baixa (14) & Muito baixa (21) & Baixa (35) & Média (42) \\
\hline
\end{tabular}

Nota. A tabela apresenta o resultado do pré e pós-testes: Prova de consciência fonológica por figuras (PCFF) e Teste de competência de leitura de palavras e pseudopalavras (TCLPP), por classificação e escore bruto.

P2 apresentou aprimoramento na habilidade de CF, como pode ser observado na Tabela 4, ao passar da classificação muito baixa no pré-teste em relação à população padrão para o ano escolar para a classificação média no pós-teste. P1 na PCFF e TCLPP manteve a classificação em relação à população padrão para o ano escolar, mas apresentou um ganho na pontuação bruta, ou seja, em relação ao número de acertos por item. Na PCFF, apresentou ganhos de oito pontos brutos e, no TCLPP, de cinco pontos. Desempenho similar foi observado em P3 que, na PCFF, também manteve a classificação em relação à população padrão para o ano escolar, mas apresentou ganho de sete pontos brutos nesse teste, o que demonstra aprimoramento da habilidade de CF. No entanto, esse participante também apresentou um aprimoramento na habilidade de leitura de palavras e de pseudopalavras, que, no pós-teste, classificou como dentro da média em relação à população padrão para seu ano escolar.

Ainda no estudo piloto, foi percebida a necessidade de alteração dos protocolos de ensino, pois, durante a atividade, o momento do registro precisava ser mais célere, favorecendo uma maior atenção da pesquisadora à aplicação da atividade em relação ao registro, porém sem perder as informaçóes referentes à aprendizagem da criança. Foram alterados todos os protocolos de rima e aliteração, dois de consciência de palavras, nenhum de consciência silábica, quatro de identidade fonêmica e três de consciência fonêmica, ambos com o objetivo de facilitar o registro no momento do ensino e posterior análise.

$\mathrm{Na}$ Fase 4, foram realizados os ajustes necessários (protocolos e atividades), percebidos durante a aplicação do estudo piloto. A necessidade de adaptação da aplicação e da forma de obtenção de resposta percebida em atividades que exigiam competências aritméticas possibilitou a adaptação e a inclusão no protocolo final. Assim sendo, nessa fase, foi construído o protocolo final, incluindo as modificações necessárias percebidas na Fase 3. Todas as modificações levaram em consideração o perfil da população, a comparação pelos juízes do treino original com o adaptado e a aplicação a um grupo clínico da população com PC, garantindo a validade de conteúdo do instrumento. 


\section{Discussáo}

Durante a validação do conteúdo do instrumento, os comandos das atividades, em todas as categorias foram disponibilizados por meio de estímulos auditivos, porém as formas de obtenção da resposta poderiam utilizar duas modalidades de processamento: vocal e não vocal. Essas adaptaçóes favoreceram a execuçáo da tarefa por parte dos participantes, como pode ser visto nos resultados aqui apresentados, e mostram a aprendizagem das crianças que passaram pelo procedimento de ensino. As utilizaçóes de estratégias similares à comunicação alternativas são descritas na literatura como vantajosas com crianças com limitaçóes motoras e/ou PC (Manzine et al., 2019).

As opçóes de respostas foram apresentadas de forma que possibilitassem a comparação de estímulo auditivo dito pela pesquisadora, com os estímulos não vocais expostos na mesa, em forma de figuras ou palavras escritas. Capovilla et al. (1998), no estudo com uma mulher com PC, que fez uso de tabuleiro como comunicaçáo alternativa, apresenta resultados de aprimoramento das habilidades de CF e escrita utilizando a comunicaçẫo alternativa como mediadora para o ensino de pessoa com PC. Almeida et al. (2005) ressaltam que as habilidades para a fala que o indivíduo tenha ou possa vir a ter não são inibidas, quando utilizada a comunicaçáo alternativa em diversos contextos. Segundo os autores, o sistema proporciona a eliminação de uma possível tensão existente no ato de comunicação, já que o indivíduo pode se expressar pela fala acompanhada da indicação de símbolos desejados. Assim sendo, foi permitido à criança responder às atividades na forma original do instrumento e utilizando a adaptação (apontar figuras ou similares), o que possibilitou à criança a utilizaçáo de uma comunicação alternativa que diminuiu a tensão da resposta oral incorreta durante a participação nas tarefas; e, ao experimentador, a possibilidade de comparação da resposta. Levando em consideração que crianças com PC possuem sequelas primárias de alteraçáo motoras, as quais interferem diretamente na fala, com maior ou menor impacto, a utilização de figuras apresentou-se como recurso fundamental.

As atividades foram construídas, em grande parte, utilizando procedimento de emparelhamento com o modelo, em que é apresentado um estímulo modelo (palavra falada) sendo requerida uma resposta de observaçáo ao modelo e apresentado um arranjo de estímulos de comparação (figuras), em que o participante precisa escolher um. Por exemplo, foi solicitado da criança que ela escolhesse entre três estímulos comparação, figuras dispostas na mesa, aquele que rimava com pato (palavra falada). Alguns autores (Neves et al., 2019; Machado \& Haydu, 2012) utilizam esse mesmo modelo de procedimento de ensino em diversas populaçôes com êxito para aprendizagem de diversas habilidades. Na população com PC, o estudo de Paixão (2012) relata o efeito de um procedimento de ensino por discriminaçáo condicional com sílabas e atividades de CF sobre a leitura generalizada recombinativa em três crianças com PC. A autora apresentou resultados positivos quanto à aprendizagem de $\mathrm{CF}$, correspondência grafema-fonema e de comportamentos novos.

Foi possível inferir que grande parte das atividades se mostrou de fácil compreensão e execução para as crianças, já que apresentaram um grande número de acertos na primeira tentativa, após as instruçóes iniciais e exemplos. Nas atividades de identidade e consciência fonêmica, os participantes necessitaram de mais tentativas para acertos dos itens, o que sugere mais dificuldades nessas habilidades, corroborando o posicionamento da literatura (Rodrigues 
\& Postalli, 2019; Seabra \& Capovilla, 2010b), que aponta a habilidade de consciência fonêmica como habilidade mais complexa em relação às supra-fonêmicas, exigindo treino estruturado e formal da correspondência entre os elementos fonêmicos da fala e os elementos grafêmicos da escrita para favorecer o aprendizado.

Outro fator a considerar-se é a relação percebida no desempenho de P3, que demonstra um aprimoramento no escore bruto de CF e em leitura de palavras e pseudopalavras diretamente proporcional, corroborando a literatura (Santos, 2019; Andrade et al., 2014; Godoy et al., 2017), que aponta a relação de reciprocidade entre processos de CF e leitura e escrita, sugerindo que ambas se fortalecem mutuamente.

Apesar de o treino estar relacionado à CF e à competência verbal, algumas atividades como as de consciência de palavras e silábica exigiam da criança competências aritméticas, como senso numérico, competência não adquirida por uma criança (P1) em sua experiência acadêmica. Para Fragoso (2019) e Ferreira et al. (2006), a competência aritmética está muito relacionada à emissão e à compreensão da linguagem. Por esse motivo, crianças com alterações na linguagem, como crianças com PC, podem apresentar dificuldade para relacionar noçóes aritméticas com as situaçóes vivenciadas no cotidiano. Neste estudo, essa dificuldade foi percebida durante o estudo piloto (resultados de P1, por exemplo), o que possibilitou a adaptação da atividade. Marchesi (2004) afirma que é necessário buscar alternativas para suprir as necessidades de ensinar habilidades essenciais ao desenvolvimento saudável do ser humano, como leitura e escrita, para pessoas que tenham o problema e as dificuldades que tiverem.

\section{Conclusáo}

O estudo aqui exposto é uma adaptação de um instrumento, que se propunha ensinar CF a diversas populaçóes, para ensinar crianças com PC, em busca de possibilitar o acesso dessa população a um instrumento amplamente testado e que se mostra eficiente no ensino da competência de CF. O instrumento é adequado à população e mantém-se ensinando o que se propunha a ensinar, o que pode ser observado tanto no processo de avaliação dos especialistas quanto durante a aplicação ao grupo piloto, uma vez que o índice de concordância dos juízes especialistas e o desempenho dos participantes na aplicação ao grupo clínico apresentaram resultados positivos.

Durante o estudo, foi possível observar possíveis falhas nos instrumentos de coleta de dados e na adaptação das atividades para a população alvo; no entanto, a utilização da análise dos especialistas e o estudo piloto permitiram observar e modificar falhas com antecedência, possibilitando a inclusão de tarefas aprimoradas na versão final. Diante do exposto, ressalta-se a importância do estudo piloto como mecanismo que permitiu testar, avaliar, revisar e aprimorar as escolhas metodológicas que implicaram a boa execução do estudo (Bailer et al., 2011).

Espera-se que esse instrumento contribua para o desenvolvimento da competência de CF de indivíduos com PC. Dessa forma, crianças com PC que necessitam desenvolver essa habilidade e que não possuem acesso a materiais adaptados para seu ensino podem se beneficiar desse instrumento, seja em ambiente terapêutico ou em sala de aula. Ressalta-se que esses procedimentos metodológicos já utilizados para testar a validade de outros instrumentos 
(Fontoura et al., 2011) permitiram testar a validade de conteúdo do instrumento de treino adaptado para crianças com PC.

Estudos futuros devem ser realizados para a verificação da generalização em outras crianças com PC, por meio da aplicação da versão adaptada do instrumento na totalidade. Além disso, sugere-se a continuidade do estudo para o aprimoramento do ensino e verificação de adaptações suplementares a crianças com PC não oralisadas, crianças com PC em idade pré-escolar e em outras populaçóes com características similares.

\section{REFERÊNCIAS}

Almeida, M. A., Pisa, M. H. A., \& Lamônica, D. H. C. (2005). Adaptações do sistema de comunicação por troca de figuras no contexto escolar. Revista Pro-Fono, 17(2), 233-240.

Andrade, E. M. A., Mecca, T. P., Almeida, R. P., Macedo, E. C. (2014). Eficácia de um programa de intervenção fônica para crianças com dificuldades de leitura e escrita. Psicopedagogia, 31(95), 119129.

Assis-Madeira, E. A., \& Carvalho, S. G. (2009). Paralisia cerebral e fatores de risco ao desenvolvimento motor: uma revisão teórica. Caderno de Pós-Graduação em Distúrbios do Desenvolvimento, 9(1), $142-163$.

Bailer, C., Tomitch, L. M. B., \& D’ely, R. C. S. F. (2011). O planejamento como processo dinâmico: a importância do estudo piloto para uma pesquisa experimental em Linguística Aplicada. Revista Intercâmbio, 24, 129-146.

Bandini, H. H., Bandini, C. S., \& Raciano-Neto, A. (2017). Relations between reading, vocabulary and phonological awareness in low-income children. Paideia, 27(68), 314-323.

Barby, A. A. O. M., \& Guimarães, S. R. K. (2016). Desenvolvimento de habilidades metafonológicas e aprendizagem da leitura e da escrita em alunos com Síndrome de Down. Revista Brasileira de Educação Especial, 22(3), 381-398. https://doi.org/10.1590/S1413-65382216000300006

Brito, D. A. (2014). Estimulando a Consciência fonológica em jovens com deficiência intelectual. [Dissertaçáo de Mestrado, Universidade do Estado do Rio de Janeiro]. Repositório Biblioteca Digital Brasileira de Teses e Dissertaçôes (BDTD). https://www.bdtd.uerj.br/tde_busca/arquivo. php?codArquivo=7951

Capovilla, A. G. S., Capovilla, F. C., Silveira, F. B., Vieira, R. S., \& Matos, S. A. (1998). Processos fonológicos em paralisia cerebral: efeitos de treino sobre consciência fonológica, leitura e escrita. Ciência \& Cognição, 2(3), 209-252

Capovilla, A. G. S. C., Gutschow, C. R. D., \& Capovilla, F. C. (2004). Habilidades cognitivas que predizem competência de leitura e escrita. Psicologia: Teoria e Prática, 6(2),13-26.

Capovilla, A. G. S., \& Dias, N. M. (2008). Habilidades de linguagem oral e sua contribuição para a posterior aquisição de leitura. Revista de Psicologia da Vetor Editora, 9(2), 135-144.

Chagas, P. S. C., Defilipo, E. C., Lemos, R. A., Mancini, M. C., Frônio, J. S., \& Carvalho, R. M. (2008). Classificação da função motora e do desempenho funcional de crianças com paralisia cerebral. Revista Brasileira de Fisioterapia, 12(5), 409-416. 
Ferreira, T. L., Capellini, S. A., \& Ciasca, S. M. (2006). Avaliação das habilidades fonológicas, de leitura e escrita em indivíduos com paralisia cerebral congênita hemiparética. Revista Psicopedagogia, 23(72), 192-2002.

Fontoura, D. R. F., Rodrigues, J. C., Fonseca, R. P., Parente, M. A. M. P., \& Salles, J. F. (2011). Adaptação do instrumento de avaliação Neuropsicológica Breve NEUPSILIN para avaliar pacientes com afasia expressiva: NEUPSILIN-Af. Ciência \& Cogniçâa, 16(6), 78-94.

Fragoso, A. O. (2019). Desempenho cognitivo e impacto da alfabetização fônica no contexto de educação de jovens e adultos na cidade de São Paulo. [Tese de Doutorado, Universidade Presbiteriana Mackenzie]. Repositório Biblioteca Digital de Teses e Dissertaçôes - TEDE Mackenzie. http:// tede.mackenzie.br/jspui/handle/tede/3919

Freire, T. (2018). Ações da fonoaudiologia na escola: programa da estimulação da consciência fonológica em escolares do $1^{\circ}$ ano do Ensino Fundamental. [Tese de Doutorado, Universidade de São Paulo]. Biblioteca Digital de Teses e Dissertaçóes USP. https://doi.org/10.11606/T.25.2018.tde01102018-211605

Godoy, D. M. A., Pinheiro, A. M. V., \& Citoler, S. D. (2017). Initial literacy: influence of phonemic awareness and teaching method. Psicologia Teoria e Prática, 19(3), 226-241.

Justino, M. I. S. V., \& Barrera, S. D. (2012). Efeitos de uma intervenção na abordagem fônica em alunos com dificuldade de alfabetização. Psicologia: teoria e pesquisa, 28(4), 399-407.

Machado, L. M., \& Haydu, V. B. (2012). Escolha de acordo com modelo e equivalência de estímulos: ensino de leitura de palavras em situação coletiva. Psicologia da Educação, 35, 72-94.

Manzine, M. G., Cruz, D. M. C., Almeida, M. A., \& Martinez, C. M. S. (2019). Programa de comunicaçáo alternativa para uma criança com paralisia cerebral e seus parceiros de comunicaçáo: um estudo de delineamento de múltiplas sondagens. Revista Brasileira de Educação Especial, 25(4), 553-570.

Marchesi, A. (2004). Da linguagem da deficiência às escolas inclusivas. In C. Coll, A. Marchesi, J. Palácios (Orgs.), Desenvolvimento psicológico e educação: transtornos de desenvolvimento e necessidades educativas especiais (pp.15-30). Artmed.

Neves, A. J., Almeida-Verdu, A. C. M., Silva, L. T. M., \& Moret, A. L. M. (2019). Ensino baseado em equivalência e produção de sentenças em crianças com implante coclear. Revista Brasileira de Análise do Comportamento, 15(1), 01-14.

Paixão, G. M. (2012). Procedimentos de ensino e teste de leitura recombinativa para crianças com paralisia cerebral. [Dissertação de Mestrado, Universidade Federal do Pará]. Repositório UFPA. http:// repositorio.ufpa.br:8080/jspui/handle/2011/10815

Pelosi, M. B., Silva, R. M. P., Santos, G., \& Reis, N. H. (2018). Atividades lúdicas para o desenvolvimento da linguagem oral e escrita para crianças e adolescentes com Síndrome de Down. Revista Brasileira de Educação Especial,24(4), 535-550. http://doi.org/10.1590/S1413-65382418000500005

Rodrigues, P. N., \& Postalli, L. M. M. (2019). Habilidades de consciência fonológica promovidas pelo ensino de leitura e escrita. Psicologia Escolar e Educacional, 23, e189961, 1-10. https://doi. org/10.1590/2175-35392019019961

Rotta, N. T. (2002). Paralisia cerebral, novas perspectivas terapêuticas. Jornal de Pediatria, 78(1), S48-S54. https://doi.org/10.1590/S0021-75572002000700008 
Santos, M. A. N. (2019). O processamento leitor de crianças do $1^{\circ}$ ano do Ensino Fundamental: descrevendo habilidades de consciência fonêmica, descodificação e compreensão leitora. [Dissertação de Mestrado, Universidade Estadual do Ceará]. Repositório UECE. https://siduece.uece.br/siduece/ pesquisarItemPublico.jsf

Seabra, A. G., \& Capovilla, F. C. (2010a). Teste de competência de leitura de palavras e pseudopalavras: TCLPP. Memnon.

Seabra, A. G., \& Capovilla, F. C. (2010b). Alfabetização: Método Fônico. Memnon.

Seabra, A. G., \& Dias, N. M. (2011). Literacy methods: definition of procedures and considerations for effective practice. Revista Psicopedagogia, 28(87), 306-320.

Seabra, A. G., \& Capovilla, F. C. (2012). Prova de consciência fonológica por figuras. In A. G. Seabra, \& N. M. Dias (Orgs.). Avaliação neuropsicológica cognitiva: linguagem oral. (pp. 132-165). Memnon.

Tabaquim, M. L. M., Ribeiro, M. V. L. M., \& Ciasca, S. M. (2016). Aprendizagem e paralisia cerebral. In: N. T. Rotta, L. Ohlweiler, \& R. dos S. Riesgo, Transtornos da aprendizagem: Abordagem Neurobiológica e Multidisciplinar (pp. 427-433). Artmed.

Recebido em: 26/06/2020

Reformulado em: 29/07/2020

Aprovado em: 17/10/2020 